\title{
Transformation of Training in the Digitalization of the Russian Economy
}

\author{
Aleksander V. Zvontsov ${ }^{1}$, Irina G. Fomina ${ }^{2}$ \\ Saint Petersburg Electrotechnical University "LETI" \\ St. Petersburg, Russia \\ ${ }^{1}$ i-fomina@inbox.ru, ${ }^{2}$ kyarhielen@mail.ru
}

\begin{abstract}
The article deals with the issues related to changing requirements for the organization and implementation of targeted training in the conditions of digital transformation of enterprises of the national economy.
\end{abstract}

Keywords- digitalization; transformation; individual educational trajectories; online learning technologies

\section{MODERNIZATION OF THE EDUCATIONAL PROCESS}

Completion of the process of digital transformation of the national economy requires a large number of highly qualified personnel not only in the areas of training directly related to mathematics and computer science, but also specialists in other areas of knowledge, as well as having a wide range of professional competencies in the field of digital technologies.

Training of such specialists, in turn, requires a significant modernization of educational processes of higher educational institutions, aimed at individualization of educational trajectories of training, the use of modern digital technologies in the learning process and the accumulated experience of the best practices of the world educational community [1].

The basis for the modernization of the educational process of higher education institutions should be provided to each student the opportunity to form their own individual educational trajectory, allowing them to develop the necessary competencies for the successful implementation of future employment.

Providing the opportunity for students to form individual educational trajectories implies the presence of the following elements in the University:

- designer of individual educational trajectories;

- designer of the individual schedule of the student;

- subsystem of analysis of digital trace of a student based on the results of his educational and scientific activity;

- the presence of the University base of local acts regulating various aspects of student learning on an individual educational trajectory;

- digital portfolio of the student.

Below is a description of each of the above elements.

\section{DESIGNER OF INDIVIDUAL EDUCATIONAL TRAJECTORIES}

\section{A. Design of the designer of individual educational trajectories}

The designer of individual educational trajectories represents the information environment providing support of construction from space of activities of educational programs (modules, disciplines, profiles), trajectories of possibilities of training recommended to the student.

When designing the designer of individual educational trajectories, it is advisable to lay in it the possibility of using artificial neural network technologies that allow, in the presence of individual preferences of the student, as well as access to his digital portfolio:

- list of possible educational trajectories;

- possible maps of competencies acquired as a result of the choice of a particular trajectory;

- the list of educational activities available as an optional (recommended) for the development of;

- the list of recommended scientific supervisors of course and final qualifying works, Tutors or consultants from among the scientific and pedagogical workers of the organization;

- the list of places of practice recommended in the framework of a particular trajectory of training.

One of the main components of the designer of individual educational trajectories is the repository of the space of educational activities provided by the University to the student [2].

\section{B. Repository of the space of educational activities}

The repository of the space of educational activities should contain:

1) A structured description of the disciplines in the form of mathematical models indicating:

- the main parameters of the disciplines (modules) established by the normative documentation (description, keywords, membership in a particular educational track (part of the curriculum), prerequisites, postrequisites required for study, 
competencies formed in the process of learning competencies;

- additional parameters of disciplines (modules): ability to work in a team, ability to prepare and present research results, etc.

2) A structural description of electives, the format for the provision of information on which corresponds to the above description of the main disciplines (modules);

3) Matrices are formed by the student in the process of learning competencies;

4) A formalized description of professional tracks offered to students in the learning process, including;

5) Summary of teachers offering the student a discipline.

It is particularly necessary to emphasize that the repository should contain information not only about the courses offered to the student (disciplines, modules) developed by the universities themselves, but also provide the student with information about the courses of leading national and foreign universities in this field of knowledge, for example, Economics, posted on domestic and international open educational platforms such as Coursera, edX, FutueLearn, NPOED, Stepik, etc.

\section{Implementation of the mechanism of individual educational trajectories}

The implementation of the mechanism of individual educational trajectories requires the use of a fundamentally new approach to the formation of the schedule of classes (consultations), the transition from group scheduling schedule on an individual basis, taking into account the characteristics of each student.

In this paradigm, the final schedule for the educational organization will be formed not on the basis of the educational programs implemented with reference to student groups, but on the basis of the students choice of a specific list of disciplines studied in the semester and the teachers who provide them. With this approach, the number and magnitude of lecture flows is determined depending on the total number of students enrolled in a particular course.

Special attention in the implementation of the mechanism of individual educational trajectories should be paid to the formation of a subsystem for collecting and analyzing the student's digital footprint based on the results of his educational and scientific activity.

Information about the educational and scientific activity of the student, including samples of works performed by him, data on the time of the beginning and completion of the received tasks, the results of writing test tasks, etc., should be recorded in the personal account of the student. Analytical processing of this information will make it possible to formulate recommendations for the student to change the individual educational trajectory of his training, based on the results achieved.

The introduction of individual educational trajectories into the educational process will also require the adjustment of the existing legal framework in universities related to the organization and implementation of the educational process. In particular, educational institutions will need to develop and implement local regulations governing the recognition of the results of online courses, developed at the sites of open learning or other educational organizations, the procedure of organization and holding of the current, intermediate and final evaluation of students on individualized education programs, the rules of formation of the individual schedule of the student, formation of a digital portfolio of a student etc.

Another element necessary for the formation of individual educational trajectories of the student is a digital portfolio containing his achievements for the entire period of study.

The practical implementation of the digital portfolio will allow potential employers (primarily strategic partners of the University) to identify talented students with a set of competencies required for further employment at an early stage, to supervise and support them during the training period (including the provision of a place to practice and perform final qualifying work).

\section{CONCLUSION}

The development of higher education in the digital transformation of the economy - a new approach to understanding and shaping the learning environment and structure of educational programs, contents of education, results of educational activities and the role of the teacher, based on the development of all participants in the educational process of digital competences.

Digital competence-skills of effective use of modern technologies, including the organization and conduct of information retrieval, processing, analysis and synchronization using digital devices and modern software, critical perception of information, the ability to create multimedia content and organize digital communications, etc.

It should be noted that the level of digital competence of students is largely determined by the level of digital competence of their teachers.

In this regard, within the framework of training for the digital economy, the question of the need to increase the level of digital competence of teachers of domestic universities comes to one of the first places.

The professional competence of the teacher in the field of digital technologies include:

- use of digital educational resources in the work of students in the classroom and remotely;

- ability to create your own digital learning materials;

- organization of students ' work in the framework of network communication projects;

- ability to involve students in the process of self-setting goals and objectives of educational activities in the digital environment;

- the ability to identify and analyze the learner's successes, difficulties, and interests through the analysis of their digital footprints; 
- the ability to individualize the educational process with the help of digital tools with a large number of students;

- be able to motivate students, including them in a variety of activities that allow them to develop the required competencies;

- be able to take an expert position on the competencies demonstrated to students in different activities and evaluate them using appropriate criteria [3].

The solution to this problem should be a large-scale program to improve the skills of teachers of domestic higher educational institutions (carried out in the form of training, retraining or internship).

\section{REFERENCES}

[1] Federal law "on education in the Russian Federation" of 29.12.2012 N 273-FL. (In Russian)

[2] Passport of the national program " Digital economy of the Russian Federation "(approved by the Presidium of the Council under the President of the Russian Federation for strategic development and national projects on December 24, 2018 No. 16). (In Russian)

[3] Passport of the Federal project "Personnel for the digital economy" (approved by the Presidium of the Government Commission on digital development, use of information technologies to improve the quality of life and business conditions, Protocol No. 9 of 28.05.2019). (In Russian) 